\title{
AUTONOMIA DO SIMBOLISMO INCONSCIENTE E EXPRESSIVIDADE NOS SONHOS SEGUNDO MERLEAU-PONTY
}

\section{THE AUTONOMY OF UNCONSCIOUS SYMBOLISM AND EXPRESSIVITY IN DREAMS ACCORDING TO MERLEAU-PONTY}

\author{
Marcos José Müller \\ http://orcid.org/0000-0001-9698-075X \\ marcos.muller@ufsc.br \\ Universidade Federal de Santa Catarina, Brasil
}

RESUMO Trata o presente artigo de um estudo sobre o modo como Merleau-Ponty busca extrair, da teoria freudiana dos sonhos, consequências ontológicas concernentes à vinculação expressiva entre as diferentes dimensões da experiência onírica, especificamente sobre o papel dos restos diurnos na descarga da libido, na realização do simbolismo ou, o que é a mesma coisa, na conversão do simbolismo em algo narrativo e sensível, especificamente afetivo. Conforme se mostrará, para Merleau-Ponty, seja no sonho sonhado seja no sonho relatado podemos verificar, entre a dimensão imaginária (afetiva e narrativa) introduzida pelos restos diurnos, por um lado, e a dimensão simbólica (ou inconsciente) expressa como significante esquecido, por outro; uma sorte de unidade sem coincidência, uma indivisão meramente expressiva. A pergunta deste artigo é - do ponto de vista ontológico - de que modo a 
indivisão expressiva entre o sonhado e o relatado dispensa o recurso à ideia de uma interioridade transparente?

Palavras-chave Sonho. Freud. Expressão. Merleau-Ponty.

ABSTRACT This article deals with a study on how Merleau-Ponty seeks to extract, from Freud's theory of dreams, ontological consequences concerning the expressive link between the different dimensions of the dream experience, specifically on the role of daytime remains in the discharge of libido, in realization of symbolism or, what is the same thing, in the conversion of symbolism into something narrative and sensitive, specifically affective. As it will be shown, for Merleau-Ponty, whether in the dreamed dream or in the reported dream, we can verify between the imaginary dimension (affective and narrative) introduced by the daytime remains, on the one hand; and the symbolic (or unconscious) dimension expressed as a forgotten signifier, on the other; a sort of unity without coincidence, a merely expressive indivisibility. The question of this article is - from an ontological point of view - how does the expressive division between the dreamed and the reported dispense the recourse to the idea of a transparent interiority?

Keywords Dream. Freud. Expression. Merleau-Ponty.

\section{Introdução}

No curso intitulado $A$ instituição, a passividade, ministrado no semestre de 1954-1955 no Collège de France, especialmente na parte que trata da experiência da passividade, Merleau-Ponty elege como temática central de seu curso a problemática do sonho. $\mathrm{O}$ que o reconduz à obra $A$ interpretação dos sonhos e aos temas metapsicológicos desenvolvidos por Freud (ESB, vs. IV-V, 1900). Diferentemente do que havia feito nos anos 1940, dessa vez MerleauPonty não reclamará para o âmbito da consciência corporal a atividade onírica que Freud, por seu turno, descreveu como um simbolismo independente. Merleau-Ponty (2000, pp. 69-70) tem agora em conta que se equivocara ao desprezar aquilo que a Freud tanto o surpreendera, a saber, a autonomia da linguagem para produzir conexões independentemente de um poder articulador, fosse ele mental ou intencional.

Em verdade, essa mudança na forma de ler Freud revela a própria crise de Merleau-Ponty (1962, p. 405) em relação à noção de consciência corporal, a qual - segundo ele próprio - tacitamente reeditava a ideia de um poder articulador, 
apenas que intuitivo ou intencional, qual cogito tácito. E é justamente a hipótese freudiana concernente à ocorrência de um simbolismo autônomo - que operaria por si tal como o revela o sonho sonhado - o que levaria Merleau-Ponty a reconhecer que a consciência corporal está acompanhada de uma sorte de "espontaneidade ensinante" (1960a, p. 94; 1969, p. 122), a qual funcionaria independentemente da primeira. De onde não se segue, para Merleau-Ponty, que ambas não estivessem interligadas. Todavia, essa interligação não se daria por conta de um cogito unificador, como aquele professado nos termos de uma teoria da intencionalidade. Nalgum sentido, para o Merleau-Ponty dos anos 1950, a consciência torna-se apenas uma das polaridades da experiência em sentido amplo. E a experiência em sentido amplo, a sua vez, passou a ser descrita como linguagem viva, simbolismo encarnado, ou "prosa do mundo" - se por 'prosa' pudermos entender um sistema de diferenciação que não está regido por uma regra de sentido, apenas pela exigência de que as diferentes polaridades envolvidas se exprimam mutuamente como parâmetros diferenciais umas das outras.

E eis então que Merleau-Ponty formula um novo operador em substituição à noção de intencionalidade, precisamente, o operador expressivo. Por meio dele Merleau-Ponty buscará entender de que modo as diferentes experiências haveriam de se comunicar, sem se equivalerem, tal como ocorre entre o sonho sonhado e o sonho relatado. O que torna decisivo para Merleau-Ponty um estudo sobre a teoria freudiana do sonho.

Ainda assim, malgrado haver se inspirado no próprio Freud para conceber a autonomia das diferentes dimensões da experiência, Merleau-Ponty acabou por se perguntar se Freud foi fiel a sua descoberta. Afinal, ao definir o simbolismo inconsciente do sono como um efeito da castração e, ato contínuo, ao definir o trabalho onírico como uma defesa contra o risco da repetição da castração, Freud outra vez lança mão de uma espécie de cogito que comandaria o sonho. Contra essa tese e em favor da radicalização da própria teoria freudiana sobre a autonomia do simbolismo inconsciente, Merleau-Ponty propõe - ele mesmo - uma releitura da teoria do sonho sob a ótica do operador expressivo. Se o simbolismo inconsciente comunica algum sentido é porque se exprime nas configurações afetivas e narrativas como diferenciação.

\section{O papel dos restos diurnos na realização dos sonhos: o método regressivo}

Merleau-Ponty (1942, p. 192) reconhece nas especulações freudianas sobre os aspectos topológicos, dinâmicos e econômicos envolvidos no sonho uma tentativa metapsicológica de se articular dois universos que, até aquele 
momento, as tradições filosófica (a partir de Descartes) e científica (a partir de Galileu) demonstraram grande dificuldade para aproximar, precisamente, os universos da natureza e o do pensamento, ou, ainda, os domínios da quantidade e da qualidade. Conforme a leitura de Merleau-Ponty, em sua teoria do sonho, Freud (ESB, v. I, 1895, p. 382) correlaciona esses dois domínios por meio de dois tipos de vetores, um deles oriundo do domínio natural, que são os afetos; e outro oriundo do domínio mental, que são as representações verbais (ou imagens verbais). Dedicar-me-ei, nos próximos parágrafos, a recuperar algo sobre a maneira como Freud articula esses vetores em uma de suas explicações sobre a possível gênese do inconsciente sistemático, tendo em vista, muito especialmente, o sonho enquanto uma das formações do inconsciente sistemático. Da mesma forma, procurarei apontar as consequências ontológicas que Merleau-Ponty busca extrair da teoria freudiana do sonho.

Começarei ensaiando uma circunstância conceitual relativa ao emprego freudiano do que aqui chamei de vetor afetivo. Antes mesmo de escrever, no capítulo VII da obra A Interpretação dos Sonhos (ESB, vs. IV-V, 1900), a primeira de suas tópicas metapsicológicas, Freud esboça uma compreensão sobre o que haveriam de ser os afetos. Conforme o ensaio postumamente publicado como Projeto de uma Psicologia Científica (ESB, v. I, 1895, pp. 332-333), os afetos - do ponto de vista topológico - teriam sua origem num sistema primário, que outra coisa não seria senão o conjunto de quantidades de tensão provocados pela estimulação física da fisiologia primária. Acontece que tais quantidades, não obstante sua tendência à descarga, nalgum momento seriam desviadas para um segundo sistema (ESB, v. I, 1895, p. 405), o sistema secundário, onde permaneceriam parcialmente retidas. É nesse segundo sistema, agora do ponto de vista dinâmico, que as quantidades de energia retidas gerariam uma espécie de registro, um tipo de inscrição especular, a que Freud chamou de afeto (Affeckt). O afeto (ESB, v. I, 1895, p. 426), então, mais não seria que a impressão (Eindruck) física causada por uma quantidade de energia circulante, quando fosse parcialmente e provisoriamente retida. Por exemplo, um estímulo doloroso, na medida que perdurasse, poderia gerar uma impressão afetiva de desprazer (ESB, v. I, 1895, p. 326).

Ora, ainda do ponto de vista dinâmico, as impressões restariam disponíveis para outro tipo de processo (ESB, v. I, 1895, pp. 332-333), o qual aconteceria no limiar do mental e do somático, no exato instante em que a impressão fosse aleatoriamente associada a estes que correspondem - do ponto de vista econômico - ao segundo tipo de vetores que antes mencionei, precisamente, as imagens verbais. Essas não são quantidades de energia, tampouco impressões físicas geradas por essas quantidades (como é o caso dos afetos). As imagens 
verbais são representações de objeto instituídas por atos mentais de associação entre representantes de coisa (como as vociferações, as escritas e os gestos) e os valores semânticos compartilhados (os quais mais não são que os significados públicos, as imagens de fala atribuídas às coisas delimitadas enquanto fenômenos). Trata-se de registros eminentemente qualitativos relativos à duração de um fenômeno do ponto de vista das gramáticas (ou recursos mentais) compartilhados pelos falantes, por exemplo, a percepção, a imaginação, o entendimento e a vontade. Não têm sua origem, portanto, na fisiologia primária, mas na linguagem social compartilhada, ou, conforme a terminologia freudiana, na esfera da consciência (ESB, v. I, 1895, pp. 507510), tal como os filósofos a descrevem, ou seja, enquanto coleção de atos mentais, malgrado as diversas topologias admitidas para esses atos: empíricos, intelectuais, transcendentais...

E, para Freud, do ponto de vista dinâmico, o mais importante a se destacar é a configuração misteriosa e, nesse sentido, mitológica (ESB, v. XXII, 1933, p. 119), que se estabelece entre os dois tipos de vetores discriminados, a saber, os afetos e as imagens (ou representações) verbais. Por exemplo, se considerarmos a ocorrência de uma experiência de dor, é como se o afeto de desprazer derivado dessa experiência - depois de algum tempo e doravante - ficasse associado a uma imagem verbal específica (ESB, v. I, 1985, p. 415). Ora, a associação entre representações verbais e impressões afetivas corresponde ao que Freud (ESB, v. XXII, 1933, p. 119), inspirado na noção brentaniana de fenômeno psíquico (e que mais não é senão um todo misterioso no limiar do mental e do somático), denominou de pulsão (Trieb). Trata-se de totalidades que, pela presença do afeto, não podem ser consideradas representações objetivas, verbais; antes uma espécie de objeto-coisa ou quase-objeto (como sugeriu Karl Abraham, em 1924), o qual perduraria de modo alucinatório entre o mental e o somático, como um tipo inédito de tensão, cuja característica é a impossibilidade de ser descarregada. Tudo se passaria como se a imagem verbal, imiscuindo-se no afeto, fizesse dele um valor cativo, capturado, o que o impediria de encontrar uma via de descarga no sistema primário. Tal como Freud (ESB, v. VII, 1905, p. 204) veio a esclarecer, alguns anos mais tarde, no antológico Três ensaios sobre a sexualidade: por mais que, em vigília, a consciência buscasse, na repetição compulsiva da sucção (fase oral), do controle muscular esfincteriano (fase anal) e da manipulação genital (fase fálica) uma forma mecânica de liberação da tensão, tal tensão não desapareceria de fato, restando como pressão constante, alojada em um nível pré-consciente (no intervalo do mental e do somático, conforme havia ensinado Franz Brentano). 
Eis por qual razão, nessa mesma esfera pré-consciente, outras imagens verbais (adquiridas a partir das interações sociais entre os falantes) unificarse-iam com o propósito de atuarem sobre as pulsões, de sorte a fragmentá-las, o que é o mesmo que dizer, de modo a separar nelas as imagens verbais e os afetos, permitindo que estes pudessem ser descarregados (ESB, v. I, 1895, p. 428). De um ponto de vista topológico, Freud denomina essas imagens verbais fragmentadoras de "ego" inibidor (ESB, v. I, 1895, p. 468). Não se trata, ainda, do sujeito do desejo, do operador do inconsciente sistemático, tal como Freud definiu o Ego vinte anos mais tarde, por ocasião da escrita da sua segunda tópica. Nesse primeiro momento, o ego inibidor é apenas uma função de defesa, uma espécie de versão pré-consciente da censura moral da consciência social. De todo modo, é na forma desse ego inibidor que, nos anos 1895, Freud (ESB, v. III, 1898, p. 90) conceberá pela primeira vez o processo de fragmentação das pulsões em benefício da descarga da tensão (afetiva) que as caracteriza. Mais tarde, Freud (ESB, v. XIV, 1917, p. 170) veio a denominar esse processo (de fragmentação das pulsões) de recalcamento (Verdrängung). E do recalque das pulsões, enfim, sobrariam, por um lado, os afetos eles próprios, agora passíveis de descarga por meio das vias somáticas do sistema primário. Mas, por outro lado, sobrariam as imagens enquanto representantes ideativos - e não mais como representações verbais (ESB, v. I, 1895, p. 426). Isso porque, para serem separadas dos afetos aos quais antes estavam vinculadas, as imagens verbais tiveram que ser "castradas" em suas consistências semânticas, o que significa dizer, separadas das imagens de fala (ou significados) a que antes correspondiam. Desse modo, depois da castração, as imagens verbais já não mais valeriam como representações verbais, já não mais funcionariam como valores propriamente semânticos, indicadores qualitativos de um atributo verbal aplicável às coisas extensas percebidas como fenômenos. Ou ainda, elas perderiam o aspecto verbal, razão pela qual - do ponto de vista da consciência - pareceriam esquecidas. Conforme a terminologia freudiana (ESB, v. XIV, 1915, pp. 105-106), depois de recalcadas, as imagens verbais seriam reduzidas a "representantes de coisa" separados de um eventual significado. Ou, ainda, as imagens verbais seriam reduzidas à condição de meros "representantes ideativos" sem vinculação verbal com uma ideia ou objeto especificado na linguagem.

Do ponto de vista econômico, entretanto, essa clivagem - ou redução das imagens verbais à condição de representantes ideativos - viabilizaria uma das mais importantes hipóteses metapsicológicas para se pensar não apenas a natureza do sonho, mas o próprio surgimento do inconsciente sistemático, qual seja, a hipótese da "libido" (ESB, v. XVIII, 1923). Tudo se passaria como se - 
depois do recalcamento, não obstante haverem sido castrados, o que significa dizer, separados de suas faculdades semânticas, perdendo assim a característica qualitativa ou mental - os representantes ideativos, mesmo assim, não perderiam o vínculo que fizeram com o domínio quantitativo das impressões afetivas. Afinal, a castração não agiria diretamente sobre as impressões afetivas, apenas sobre as características semânticas das representações verbais, agora reduzidas a representantes de coisa. E por conseguinte, mesmo semanticamente castrados, tais representantes seguiriam podendo abrigar a tensão quantitativa das impressões afetivas a que estavam associadas. O que, todavia, não haveria de suceder, pois os afetos, agora liberados pela castração da prisão semântica em que antes se encontravam, alcançariam as vias de descarga do sistema primário (musculoesquelético). De toda sorte, tal não impediria que se produzisse, junto aos representantes ideativos recalcados, uma espécie de novo registro quantitativo - dessa vez relativo à perda da tensão característica dos afetos. O nome que Freud dá a esse novo registro é "libido". Tratar-se-ia do registro quantitativo de uma ausência, da ausência dos afetos junto aos representantes ideativos recalcados. Vale aqui sublinhar que, para Freud, tal ausência não teria que ver com a imagem verbal perdida e, sim, com o afeto a que os representantes ideativos estavam antes vinculados. Para dizê-lo outra vez, de um modo sintético, do ponto de vista econômico, depois do recalcamento, os representantes ideativos recalcados passariam a carregar, enquanto dimensão negativa, um tipo de registro do afeto do qual foram separados, uma espécie de "saudade" ou "falta", a qual Freud denominou de libido (ESB, v. XVIII, 1923, p. 308). E a libido é a energia que viabilizará - agora do ponto de vista dinâmico - a emergência do desejo inconsciente.

De fato, do ponto de vista dinâmico, é justamente a libido o que faria cada representante ideativo recalcado buscar a outro representante ideativo (recalcado ou não), como se, associando-se a este, produzindo nele uma catexia, algo do afeto perdido - e do qual o representante ideativo recalcado fora separado - pudesse ser recuperado de "modo fantasmático". A tal busca, Freud chamou de desejo. Mas de um desejo que não é consciente (ESB, vs. IV-V, 1900, p. 602). Afinal, não está governado por um ato de consciência, por uma representação verbal não recalcada. Tampouco está regido por um estímulo advindo do processo primário ou por uma impressão afetiva advinda do processo secundário. O desejo do qual Freud aqui nos fala tem que ver com a busca libidinal empreendida pelos representantes ideativos que foram recalcados, como se eles pudessem encontrar, junto a outros representantes, sejam estes recalcados ou não, um poder semântico que lhes valesse a possibilidade de capturar o afeto de que foram separados (ESB, vs. IV-V, 1900, p. 603). O que 
implica admitir a existência de um sistema meramente simbólico, mas não consciente, ao qual Freud então denominou de inconsciente sistemático. Ora, o melhor exemplo para ilustrar a ocorrência do desejo inconsciente, do desejo enquanto busca simbólica ou vínculo libidinal entre representantes ideativos recalcados, Freud o encontra justamente no sonho (ESB, v. I, 1985, pp. 447449). O sonho, conforme a antológica formulação de Freud, é uma espécie de realização de desejos inconscientes (ESB, vs. IV-V, 1900, p. 107).

Aliás, se levarmos em conta o momento histórico e os motivos programáticos de Freud, o sonho é a própria prova da existência do inconsciente sistemático. Afinal, no sono, no instante em que as imagens (ou representações) conscientes estivessem em repouso, nada justificaria uma sorte de atividade representacional que não a admissão de um "outro" sistema simbólico, independente da consciência. Para dizê-lo de outro modo, se no sono podemos verificar qualquer tipo de atividade envolvendo representantes ideativos, isso não tem mais que ver com a consciência. Do ponto de vista topológico, trata-se de outro sistema, de "outra cena", como diria Freud (ESB, v. II, 1893-1895, p. 48, e v. XI, 1910 , p. 18), na qual os representantes ideativos recalcados operariam de modo autônomo, como um sistema inconsciente, como o inconsciente sistemático. $\mathrm{Ou}$ ainda, nesse sistema inconsciente, os representantes ideativos - por haverem sido recalcados - não operariam mais como imagens imbuídas de valor semântico, não operariam mais como "representações de coisas" unidas a "representações verbais correspondentes" (ESB, v. XIV, 1915, p. 105-106):

Acreditamos saber agora como uma representação consciente se distingue de uma inconsciente. [...] A representação consciente abrange a representação da coisa mais a representação da palavra correspondente, e a inconsciente é apenas a representação da coisa.

No sistema inconsciente, os representantes ideativos recalcados operariam como significantes investidos de valor libidinal. O que significa dizer, agora do ponto de vista econômico, os representantes ideativos apresentar-se-iam investidos de uma falta relativamente ao afeto com o qual estavam imbricados antes do recalcamento imposto às pulsões pré-conscientes e que eles próprios integravam (enquanto imagens verbais). É como se, agora do ponto de vista dinâmico, os representantes ideativos recalcados retornassem cada qual como "significante" do que faltasse ao outro, associando-se de modo livre (em relação às regras sintáticas e semânticas que caracterizam a linguagem consciente) em proveito de substitutos (fantasmáticos) da unidade pulsional agora perdida - e que antes integravam. O que faria retornar a tensão. Afinal, a libido compartilhada na associação livre entre os representantes ideativos 
não encontraria um objeto (semântico) que a realizaria enquanto sentido, tampouco uma coisa (física) que a preenchesse materialmente. Haveria que se buscar tal sentido ou tal ocorrência física. Mas, como fazê-lo se o sonhador está adormecido? Como descarregar essa tensão se tanto a consciência/préconsciência quanto o sistema primário estariam adormecidos?

Eis aqui a hipótese fundamental de Freud (ESB, v. IV-V, 1900, pp. 580-583) para explicar, do ponto de vista dinâmico, o trabalho do sonho, o qual consiste numa "regressão" dinâmica, como se os novos objetos alucinatórios produzidos de modo meramente simbólico (pela força da libido que os caracterizasse) pudessem inverter o caminho progressivo de busca de vias conscientes e musculares de descarga. Tal significa dizer que, em vez de forçarem o sistema consciente e a musculatura (agora adormecidos) a desempenharem a descarga da tensão (e que só poderia ocorrer em estado de vigília), os representantes ideativos - na condição de significantes uns dos outros e amalgamados enquanto objetos alucinatórios, oníricos, pulsões meramente simbólicas e investidas de tensão libidinal - retornariam aos restos diurnos, entendendo-se por restos diurnos tanto os conteúdos de memória quanto os traços de impressões afetivas ainda disponíveis (nos "estertores" do sistema primário e da consciência/préconsciência) e nos quais as pulsões simbólicas pudessem encontrar "apoio" (Anlehnung) (ESB, v. VII, 1905, p. 187). É junto a esses restos diurnos apoiados neles - que os representantes ideativos alcançariam descarregar a tensão libidinal de que estavam investidos, porquanto "realizariam" uma configuração ao mesmo tempo física e mental. A configuração física estaria assegurada pelos afetos remanescentes da vigília. A configuração mental, pelos restos de memória ainda disponíveis.

Ora, reside justamente aqui, na hipótese freudiana - segundo a qual os objetos oníricos haveriam de buscar "apoio" em restos diurnos, o que inclui os afetos e imagens verbais advindas da memória recente -, a razão pela qual, na avaliação de Merleau-Ponty, no campo do sonho, a realização de um desejo não é uma experiência exclusivamente simbólica. Merleau-Ponty defende aqui a ideia de que, tal como o revela a descrição freudiana do movimento regressivo dos representantes ideativos recalcados, no âmbito do sonho, esses mesmos representantes buscam apoiar-se em elementos advindos da fisiologia primária e da consciência/pré-consciência, simultaneamente. O que caracterizaria o vínculo não associativo, não metonímico, não metafórico, enfim, não simbólico - a que Merleau-Ponty chama de "expressivo" - entre a própria atividade simbólica (inconsciente) dos representantes ideativos no sonho e aquilo em que tal atividade apoia-se, precisamente, a alteridade do afeto e das imagens advindas da memória recente. Nalguma medida, no sonho, os 
afetos (resultantes da modificação da fisiologia primária) e as representações verbais remanescentes (da memória recente), não obstante apresentarem-se de modo estranho, porquanto desacompanhados da qualidade da vigília, impõemse aos significantes recalcados como vias de descarga, assim como se impõem enquanto modo de manifestação do próprio mundo, ainda que se trate de um mundo em decomposição. De onde se depreende a ideia de uma indivisão não sintética ou expressiva entre tais elementos.

Alcanço aqui a chave de leitura por cujo meio Merleau-Ponty apropriase da teoria freudiana do sonho. Trata-se da tese sobre a indivisão entre o simbólico e o narrativo/afetivo. Por meio dessa tese, Merleau-Ponty evidencia o papel dos restos diurnos na descarga da libido, na realização do simbolismo ou, o que é a mesma coisa, na conversão do simbolismo em algo narrativo e sensível, especificamente afetivo. Merleau-Ponty ensaia, assim, mais do que uma releitura da teoria freudiana do sonho, uma teoria ontológica sobre a relação precária e ambígua da linguagem como o mundo não linguageiro. O que, entretanto, exigirá o afastamento de Merleau-Ponty em relação ao operador com o qual Freud buscou definir o trabalho onírico de descarga de libido ou, o que é a mesma coisa, de dispersão da libido por meio de produções fantasmáticas, qual seja tal operador, a noção de castração simbólica. Afinal, tal noção não leva em consideração a importância do mundo que se apresenta nos restos diurnos.

\section{A insuficiência da noção de castração simbólica para se pensar o trabalho onírico}

Nos anos 1950, não obstante haver suspendido a perspectiva crítica desde a qual antes se ocupara dos textos de Freud, muito especialmente a tese de que as noções causais inerentes à metapsicologia reduziriam as descobertas da psicanálise à condição de uma metafísica, Merleau-Ponty (1945, p. 192) - ainda assim - mantivera sua objeção ao primado que, supostamente, Freud teria atribuído à dimensão simbólica do inconsciente. Muito especialmente, no que tange à atividade onírica, Merleau-Ponty relativizara o destaque reclamado por Freud para a noção de recalcamento ou castração simbólica. Isso porque, mesmo tendo reconhecido o papel desempenhado pelos restos diurnos, ao definir o trabalho onírico (de produção de sentido fantasmático) enquanto uma resposta ao recalcamento (ou castração simbólica), Freud teria dado a entender que toda atividade onírica estaria, nalgum sentido, comprometida com o reestabelecimento ficcional de uma unidade (pulsional) originalmente perdida, recalcada. O vínculo entre o trabalho onírico e o recalcamento, nesse 
sentido, reintroduziria a ideia de que o sonho funcionaria como correlato de um cogito linguageiro, o qual, não obstante ter sido esquecido (recalcado) em seus aspectos semânticos, revelar-se-ia no sonho investindo-o de uma coerência interna, o que - conforme Merleau-Ponty - reeditaria o pensamento convencional de identidade.

De fato, não obstante esclarecer, no decurso dos sete livros que compõem a Interpretação dos sonhos, que o analista não se ocupa do sonho sonhado, mas do sonho relatado, mesmo admitindo que o sonho relatado é confuso, apresentando-se ininteligível ao analista e ao próprio sonhador, Freud sempre foi partidário da tese de que os sonhos sonhados têm um "sentido" (ESB, vs. IV-V, 1900, p. 107). Se o sonhador não o alcança, ou se o relato sobre o sonho sonhado se apresenta ininteligível, tal inacessibilidade é produzida pelo próprio relato, como forma de censura contra o que foi sonhado. Por conseguinte, nalguma medida, o sonhador tem ciência de um sentido que ele próprio recusa ou não pode saber. De onde se seguiria que o trabalho do analista seria permitir que esse "sentido" censurado pudesse se dizer. Muito embora, para Freud, a enunciação do sentido censurado não guardasse relação alguma com o sentido (racional) produzido no âmbito da consciência verbal. Nesta, o sentido é o efeito de uma operação lógica de associação entre representantes de fala (como os sons e os gestos) e imagens semânticas (como os significados). $\mathrm{O}$ que permitiria ao hermeneuta, por exemplo, inferir a conexão global das palavras empregadas em um relato. Ou, ao decifrador, que lhe fosse possível emprestar significados - advindos de um modelo ou gramática já formulados - aos representantes de fala empregados em um relato. Já o sentido formulado no sonho sonhado - conforme Freud - é de outro tipo (ESB, vs IV-V, 1900, p. 111). Ele tem que ver com a realização de um desejo inconsciente, o que significa dizer: com a realização de conexões entre representantes ideativos entre si, sem qualquer associação com imagens semânticas, sem qualquer carga de significados. De onde se depreenderia o caráter alucinatório, fantasmático, meramente simbólico do sentido formulado nos sonhos. Merleau-Ponty (2000, pp. 69-70), nesse ponto, é um entusiasta de Freud, uma vez que este nos teria levado a reconhecer, no sonho, a autonomia da linguagem para se articular independentemente das leis e convenções semânticas:

[...] $]$ que Freud trouxe de mais interessante, - não a ideia de um segundo "eu penso" que seria aquilo que nós ignoramos de nós -, mas a ideia de um simbolismo que seja primordial, originário de um "pensamento não convencional" [...].

Todavia, para a frustração de Merleau-Ponty, o simbolismo primordial apresentado por Freud, malgrado distinguir-se do pensamento convencional 
regido pela lógica, ainda assim apresentar-se-ia rigidamente estruturado. E o que ao sonho lhe estruturaria é aquilo mesmo que o originara, precisamente, a castração simbólica das imagens verbais, as quais, devido à castração, foram agora reduzidas a significantes de fala (ou, o que é a mesma coisa, representantes ideativos). Tal significa dizer que, para Freud, não obstante os representantes ideativos (que operam no sonho) não obedecerem às leis lógicas de combinação entre valores semânticos, eles ainda assim estariam organizados segundo um parâmetro, que é o recalcamento (dos aspectos semânticos da linguagem) ou, simplesmente, castração simbólica. Por um lado, a castração é a origem do sistema de representações recalcadas que constituem o inconsciente (do sonho). Por outro, na medida em que ela sempre pode sobrevir à linguagem, inclusive à linguagem inconsciente, a castração simbólica determina a finitude das conexões simbólicas entre os representantes recalcados, impondo-lhes um limite, uma ameaça, o que levaria Freud a inferir que, nalgum sentido, por meio das múltiplas conexões, os representantes recalcados buscariam simultaneamente "substituir" a unidade pulsional castrada e "neutralizar" o retorno da castração por sobre a pulsão substituta. Noutras palavras: ao mesmo tempo que buscariam restituir aquilo que a castração dos aspectos semânticos lhes quitou (muito especialmente a vinculação com as impressões afetivas a que antes estavam unidos e que restaram apenas como registro negativo ou, simplesmente, libido), os representantes recalcados operariam de modo a evitar que a castração lhes ocorresse novamente. De onde se segue, portanto, que os representantes recalcados, no sonho, articular-se-iam em torno de dois propósitos. Primeiro, a produção de uma pulsão substituta - e que Freud chama de pulsão sexual, porquanto ela sempre está carente de algo que a pudesse realizar, completar. E, segundo: a utilização desta pulsão substituta para neutralizar a ameaça da repetição da castração - o que deslocaria a pulsão sexual à condição de pulsão de conservação do sistema inconsciente. A pulsões (substitutas) sexual e de conservação corresponderiam, então, aos dois objetos fundamentais do desejo que o sonho realizaria (e que, mais tarde, por ocasião da segunda tópica, Freud reuniria sob um mesmo nome: pulsão de vida).

Merleau-Ponty, a sua vez, não se sente totalmente à vontade com essa maximização freudiana da castração simbólica. De fato, não obstante MerleauPonty admitir que a noção de castração dos aspectos semânticos das imagens ou representações verbais tenha se mostrado eficiente para explicar a gênese do inconsciente sistemático, mesmo sendo plausível que a libido compartilhada pelos representantes recalcados tenha sua origem na castração dos aspectos semânticos das imagens verbais, daí não se segue - para o filósofo - que a castração simbólica seja suficiente para explicar a formação dos objetos 
oníricos. Ou, ainda, daí não se segue que a conectividade onírica (responsável pela dispersão da libido) seja comandada exclusivamente pela castração simbólica. É o próprio Freud quem o admite quando recorre à ideia de que, para constituírem um objeto onírico, os representantes recalcados necessitam buscar "apoio" junto aos restos diurnos.

Do mesmo modo, segundo Merleau-Ponty, se é verdade que a castração sempre pode se repetir e, por conseguinte, impor à atividade simbólica dos representantes recalcados um limite, tal não significa que o limite em questão esteja relacionado à interdição da busca por um substituto simbólico daquilo que originariamente foi recalcado. Afinal, as formas de articulação simbólica entre os representantes recalcados - ainda mais quando apoiadas em restos diurnos - pode servir a diferentes propósitos. Por consequência, se é plausível que, no sonho, os representantes recalcados busquem se defender da castração, daí não se segue que toda articulação onírica seja uma defesa contra a castração especificamente simbólica. Tal só aconteceria se admitíssemos, de antemão, que houvesse, entre os representantes recalcados, uma sorte de compromisso com o reestabelecimento simbólico da unidade pulsional perdida. Por outras palavras: tal só aconteceria se admitíssemos, de antemão, que houvesse, entre os representantes recalcados, uma sorte de compromisso com o reestabelecimento da unidade verbal recalcada. O que aos olhos de Merleau-Ponty parece problemático. Tratar-se-ia de uma tácita adesão do freudismo ao "pensamento convencional de identidade", como se o sistema inconsciente devesse responder a um motivo ou causa que lhe desse unidade, ou que fizesse dele um "sujeito", uma sorte de segunda consciência ou cogito. Eis em que sentido, dirá MerleauPonty (2000, p. 203):

Crer que o simbolismo vem apenas do recalque, e crer que o recalque traz de volta ao estado simbólico ou onírico como simples privação, é pura falsidade em relação à consciência da vigília sempre possível. Esses dois erros supõem prioridade do pensamento convencional por identidade.

Contra o primado da castração simbólica, o qual exige da linguagem a sua unidade, sua subjetividade, contra a presença recalcitrante na psicanálise do "pensamento convencional da identidade", uma vez que Freud compreende o inconsciente enquanto um sistema que busca restituir de forma fantasmática o objeto pulsional perdido, Merleau-Ponty vai reclamar o reconhecimento de que, ao menos entre os representantes recalcados e os restos diurnos, opera um "vínculo precário", o qual não pode ser pensado a partir da ideia de identidade ou unidade. Nalgum sentido, os restos diurnos emprestam aos significantes um lastro de imagens e impressões que deslocam a libido para um campo 
muito mais amplo de possibilidades que a mera substituição de algo perdido, ou a defesa contra o risco da repetição da castração. Ou, os restos diurnos emprestam aos representantes recalcados caminhos que, de outra maneira, só seriam possíveis em contexto de vigília, como se, na conjunção entre os representantes esvaziados de valor semântico e os restos diurnos houvesse uma sorte de passagem ou comunicação difusa que dá ao sonho um aspecto de espontaneidade mundana. Merleau-Ponty vai dizer que, no sonho, os restos diurnos asseguram uma espécie de vínculo de indivisão expressiva entre os representantes recalcados e a presença recalcitrante do mundo, o que faz do sonho uma zona tão existencial quanto à vigília, apenas que sem o consórcio ou regência de atos mentais de uma consciência transparente para si. Ora, mas o que haveria de ser este vínculo de indivisão expressiva admitido por MerleauPonty entre os elementos constitutivos do sonho?

\section{Expressividade dos sonhos}

Para Merleau-Ponty, nos sonhos, os representantes ideativos recalcados e aos quais o filósofo, mais próximo da linguística, chama de "significantes" recalcados - não desempenham apenas funções simbólicas. Os significantes recalcados também "exprimem" algo que os ultrapassa, como se trouxessem consigo um excesso que não é ele mesmo um significante; antes, uma "força assertórica" a que são passivos - e que Merleau-Ponty relaciona às noções freudianas de afeto e de memória remanescente. Mas o que se deve aqui entender por expressão?

Tomada de empréstimo a Gottfried W. Leibniz (1714), a noção de expressão deveria designar, nos escritos de Merleau-Ponty, primeiramente o "lugar" e, nas obras depois de 1945, a "dinâmica" por meio da qual as diferentes dimensões da experiência perceptiva e cultural haveriam de conviver e se diferenciar, sem que isso implicasse a admissão do primado de uma sobre a outra ou o recurso a um princípio articulador que lhes assegurasse a unidade ou harmonia. E o que mais interessava a Merleau-Ponty no uso leibniziano da noção de expressão era precisamente o fato de ele designar um possível vínculo entre o si e o alter, sem que tal vínculo implicasse a redução de um ao outro, ou a síntese em um terceiro, o que faria regressar uma tese metafísica. Para Leibniz, conforme a leitura que dele fez Husserl (1931, p. 126) e da qual se apropriou MerleauPonty (1969, p. 41), exprimir é manifestar, de maneira negativa junto a cada significante empregado, o todo ao qual esse significante pertence, sem que esse todo precise ser explicitado, explicado, representado. Conforme a terminologia de Leibniz, exprimir é manifestar, de maneira negativa junto a cada mônada, 
as demais mônadas das quais a mônada em questão se diferencia e junto às quais adquire singularidade. Todavia, como mais tarde sinalizou Merleau-Ponty (1964a, p. 276), o próprio Leibniz não soube vislumbrar o alcance da noção que introduziu, vindo a retroagir em favor de um princípio regulador, o qual impor-se-ia às mônadas como garantia da harmonia onto-teológica das mesmas. Eis por que, num primeiro momento, para desvincular a ideia de expressão de toda e qualquer teleologia, Merleau-Ponty buscou pensá-la como o efeito da condição ambígua do corpo próprio, ao mesmo tempo impessoal e pessoal em sua inserção nos mundos da percepção e da cultura.

De fato, na obra Fenomenologia da percepção, Merleau-Ponty (1945, p. 221) descreve o corpo como um espaço eminentemente expressivo. $\mathrm{O}$ sentido último dessa expressividade é o formato temporal dos movimentos de transcendência que, a partir de um fundo habitual, o corpo atual desencadeia em direção a um porvir. A expressão é o poder espontâneo, por cujo meio o corpo faz "um passado e um futuro existirem para um presente" ou, trata-se de uma capacidade do corpo para atar "em conjunto um presente, um passado e um futuro" (1945, p. 276) Desse modo, o corpo "secreta tempo ou, antes, torna-se este lugar da natureza em que, pela primeira vez, os acontecimentos, em lugar de impelirem-se uns aos outros no ser, projetam em torno do presente um duplo horizonte de passado e de futuro e recebem uma orientação histórica" (1945, pp. 276-277).

Todavia, se o corpo perceptivo é essa unidade ambígua de hábito e de atualidade; se ele é esse poder que temos para nos colocar na transcendência, mas a partir do que temos de próprio; se o que temos de próprio é impessoal, por conseguinte de todos, em que sentido podemos dizer que as significações expressas encontram nele um fundamento, um local de fundo, a típica de todo e qualquer campo fenomenal? Não seria antes a unidade ambígua do corpo - sua capacidade para retomar na atualidade uma orientação advinda de outro momento e de outro lugar - algo fundado nas relações expressivas da experiência perceptiva?

Ora, diz Merleau-Ponty (1962, p. 409) no texto que submeteu ao Collège de France, o estudo topológico do mundo da percepção (expresso na ambiguidade do corpo próprio) resguarda uma "má ambiguidade". A busca do "lugar" da expressividade implica um domínio indecidível entre o pré-pessoal e o pessoal, o singular e o universal. Ainda assim, propõe Merleau-Ponty (1962, p. 409), "há, no fenômeno da expressão, uma 'boa ambiguidade', isto é, uma espontaneidade que realiza o que parecia impossível, a considerar os elementos separados, que reúne em um só tecido a pluralidade das mônadas, o passado e o presente, a natureza e a cultura". Todavia, para que a ambiguidade - característica da dupla 
inserção do corpo na natureza e na cultura - se mostre boa, a expressão deve poder ser entendida para além do corpo. Ela não pode se limitar a descrever a dinâmica corporal. É preciso reconhecer que a expressão é a dinâmica da própria generalidade, da relação de coexistência que embaralha os corpos, os significantes e o mundo. E eis que, em textos como $A$ dúvida de Cézanne, $O$ romance e a metafísica (publicados na obra Sinais, de 1960), Humanismo e Terror (1947), todos eles escritos depois de 1945, Merleau-Ponty se propõe não mais restituir o mundo da percepção tal como o corpo o exprime, mas mostrar "como a comunicação com outrem e o pensamento retomam e ultrapassam a percepção que nos iniciou na verdade" (1962, p. 402).

De fato, nos textos depois de 1945, o acento nos estudos sobre a expressividade não se encontra mais no corpo como locus da expressão. Voltase, sim, para a práxis comunicativa como dinâmica da expressividade. O que se faz notar na maneira como, paulatinamente, Merleau-Ponty deixa de lado a discussão com a psicologia da linguagem para polemizar com a semiologia de Saussure. Evidentemente, o que interessa a Merleau-Ponty em seus estudos linguísticos não é explicar o funcionamento dos sistemas de signos, mas compreender como a expressividade possa ser um efeito da diferenciação entre os significantes. O que exigiu de Merleau-Ponty deslocar da gramática para a comunicação a seara das discussões sobre a natureza da expressão (1962, p. 405). Afinal, em seu recorte sincrônico da língua, Saussure limita-se a mapear os diferentes grupamentos diferenciais, sem explicar como eles se estabeleceram, sequer como se mantêm. O recorte diacrônico, com seu viés histórico, limita-se a mostrar a relação entre grupamentos diferenciais já estabelecidos. Não toca na questão da gênese e da autossustentação dos mesmos. Portanto, vai dizer Merleau-Ponty, para se alcançar a gênese da expressividade, é preciso apanhar a linguagem em funcionamento, compreendê-la de dentro, desde a posição de quem a exerce. O que deslocará para a fala o que a semiologia de Saussure só admitia para a língua, a saber, a investigação das condições dinâmicas que dão sistematicidade à linguagem. Por isso encontramos, em contrapartida de uma diacronia da língua, não mais uma sincronia também da língua, mas da fala. Na fala, segundo Merleau-Ponty (1960a, p. 111), há um duplo envolvimento entre sincronia e diacronia, que faz da comunicação um sistema em ato, aberto e temporal, de tal modo que a contingência possa invadi-lo e ele se alterar.

E o que Merleau-Ponty conquista, por meio desse deslocamento em direção a uma sincronia da fala, é aquilo que a gramática velava no âmbito da língua, precisamente, a temporalidade assíncrona da comunicação. Quando nos colocamos na condição daquele que tem de produzir uma significação para quem ainda não a possui, ou compreender o que se figura para nós como uma articulação inédita, não temos outra alternativa senão recorrer a significantes 
não atuais, a processos de diferenciação que estão em outro tempo e que, portanto, estariam a princípio excluídos do recorte sincrônico. De onde se segue que: se é verdade que a diferenciação entre os significantes é o segredo da sistematicidade da linguagem, se é por meio dessa diferenciação que um significado se exprime como um todo, o acontecimento da diferenciação não é efeito de série de sucessivos (diacronia) nem de disjuntivos (sincronia). É decorrência da práxis falante, da espontaneidade que a práxis comunicativa empresta aos falantes, facultando-lhes compartilharem signos trazidos de outros tempos, bem como perfis trazidos do mundo impessoal da percepção, tudo isso em proveito de falas novas e ambíguas, ao mesmo tempo simbólicas e sensíveis. O que implica admitir que, na comunicação, cada falante habita um tempo alargado, ao qual pode convocar em benefício da delimitação de uma diferença e ao qual pode exprimir como parâmetro para a delimitação de uma novidade. A expressividade não é mais uma virtude do corpo, mas daquilo que o corpo pode repercutir como parâmetro para a sua própria singularidade, a saber, o tempo descortinado pela comunicação.

Ora, estamos já aqui diante de uma outra maneira de se entender a expressividade. A expressividade característica da comunicação - e na forma da qual nos descobrimos implicados como uma só comunidade de possibilidades - não é um predicado dos corpos falantes, mas do campo de indivisão temporal formado entre o cultural e o pré-pessoal. A expressividade é tal campo ele mesmo, a "atividade de diferenciação originária" (1969, p. 47) e segundo a qual, para que algo possa se diferenciar de outra coisa, precisa simultaneamente chamar à liça essa mesma coisa ou outra coisa ainda da qual se diferencia, o que inclui o mundo impessoal da percepção, como se, nalgum sentido, estivesse lateralmente a eles vinculada (1960a, p. 51), formando com eles uma indivisão sem síntese, sem coincidência, um campo de indivisão em benefício da diferenciação continuada, o que faz de cada significante uma pars totalis de uma omnitudo realitatis que está na "intersecção e no intervalo das palavras" (1960a, p. 53).

Vale aqui destacar que o campo de indivisão - essa omnitudo realitatis expressa na diferenciação - já não é mais pensado como lugar, síntese entre existentes, mas como dinâmica de diferenciação, a qual, para existir, evoca a coexistência entre aqueles que se diferenciam, coexistência esta à qual MerleauPonty denomina de 'prosa' (1969, pp. 22-23). Cada existente exprime aquilo ou aquele de que se diferencia, como se a existência do diferente estivesse implicada - mas não representada ou contida - na própria ipseidade daquilo que dele se diferenciou. É o que ocorre - conforme a ilustração proposta por Merleau-Ponty - com as cromátides sexuais resultantes do quiasma (ou da reversibilidade de seus materiais genéticos ocorrida na fase conhecida pela 
Biologia como 'prófase da meiose II'). As cromátides resultantes do quiasma carregam - cada qual e parcialmente - aspectos das outras cromátides de que se diferenciaram, motivo por que se exprimem mutuamente sem se identificarem. Eis aqui, inclusive, a figuração que dará lastro às formulações tardias de Merleau-Ponty (1964a, p. 315) e que o levarão a pensar a expressão mais além de uma dinâmica descritiva da gênese da significação no mundo simbólico. Apoiado na metáfora biológica do quiasma, Merleau-Ponty elevará a noção de expressão à condição de operador formal de uma ontologia da diferenciação, a qual incluirá, inclusive, o processo de diferenciação expressiva entre o mundo impessoal da percepção e o mundo simbólico da cultura. O que fez Merleau-Ponty (1964a, p. 315) retornar a Leibniz para dizer, contra ele, que: se o mundo sensível e o mundo simbólico se exprimem mutuamente, tal não é consequência da harmonização divina, mas do quiasma, afinal, o quiasma é a verdade da harmonia preestabelecida-Bem mais exata que ela: porque ela está entre fatos locais -individuados, e o quiasma liga como avesso e direito conjuntos antecipadamente unificados em vias de diferenciação. $\mathrm{Ou}$ seja, enquanto quiasma, a expressão não seria a manifestação do todo no indivíduo, pois isso implicaria estabelecer a divisão e a harmonia das partes antes mesmo da expressão. Ao contrário, a expressão seria o momento de eclosão das singularidades, as quais, todavia, sempre anunciam aquilo de que se diferenciam, denunciando assim o campo de indivisão do qual participam e que não é da ordem da síntese, mas da diferenciação continuada.

E é justamente a partir da ótica da indivisão expressiva que Merleau-Ponty interpreta a teoria freudiana relativa ao método regressivo implementado pelo sonho. Se os significantes recalcados podem regressar aos afetos e aos traços de memória, se aqueles podem apoiar-se nestes, tal significa que todos eles compartilham entre si um vínculo expressivo, tal como o fazem as cromátides sexuais no processo de reversibilidade ocorrido na prófase da meiose II. Nalgum sentido, se os objetos oníricos conseguem dispersar a tensão libidinal (que os caracteriza) por meio dos afetos e dos traços de memória, e se os afetos e a memória recente se fazem sentir junto aos objetos oníricos, tal se deve a que os restos diurnos se exprimem por meio dos significantes recalcados e vice-versa.

Freud descobriu o simbolismo positivo; esse sentido além do sentido tem duplo sentido. Normalmente, lembramos apenas os dois sentidos separados: sentido manifesto e sentido latente. Este [seria] restituição de um sentido original que foi em seguida recalcado, escondido na memória, por censura. Inconsciente e censura, dois parceiros, dois textos, - condensação, deslocamento - dois sentidos que têm mesma estrutura: “consciência de...”. Freud apresentou as coisas assim. Contudo, sua descoberta não é essa: se o conteúdo latente estivesse verdadeiramente escondido, o sonho não traria nenhum relaxamento ao desejo. É preciso que o conteúdo latente lhe seja de alguma maneira acessível: que aquele que sonha e aquele que vive no fundo do sonho sejam 
o mesmo. Que não haja, verdadeiramente, duas pessoas (o inconsciente e a censura, o id e o eu), mas comunicação entre eles. A censura supõe noção prévia do censurado. Mas essa noção prévia não é noção (Merleau-Ponty, 2000, pp. 201-202).

Para Merleau-Ponty, a dimensão simbólica e a dimensão narrativo/afetiva compartilham um tipo de implicação sem coincidência. De onde não se segue que reeditem uma espécie de consciência tácita, investida de transparência. A transparência exigiria a possibilidade da coincidência. $\mathrm{O}$ que não é o caso da indivisão entre o simbólico e o narrativo/afetivo no sonho. Indivisão diz tão somente respeito àquilo que, ao se diferenciar, exprime-se mutuamente. O que significa que a expressividade é a qualidade dos elementos variados que se implicam como diferença, sem coincidência, sem transparência.

Aliás, o sonho é para Merleau-Ponty a prova de que a transparência não é uma condição para a realização de um sentido. O que o opõe a Sartre (1940, pp. 22-229). Diferentemente deste - para quem o sonho é uma consequência da eclipse da consciência imageante, a qual, adormecida, o que significa dizer, desprovida de sua transparência constitutiva, não lograria apontar o objeto adequado de sua intencionalidade, deixando-se, portanto, fascinar pelas imagens remanescentes da memória - Merleau-Ponty (1968, pp. 67-68) acredita que "a negação do mundo, no sono, é também uma maneira de mantêlo, e a consciência dormente não é, pois, um refúgio do nada puro, ela é repleta de resquícios do passado e do presente, jogando com eles". Mesmo desprovido da suposta transparência da vigília, o sonho opera como uma fala falante, produtora de narrativas simbólicas e afetivas, o que demonstra a irrelevância da noção de transparência para a produção do sentido. E o sentido que se articula de forma inconsciente no sonho é a indivisão expressiva entre diferentes classes de elementos, os quais se apoiam sem se fundirem, mesclam-se sem se igualarem no interior de um todo não transparente. Ademais, é justamente essa mesma indivisão expressiva - especificamente entre o simbólico e o narrativo/ afetivo - o que possibilita a passagem do sonho sonhado ao sonho relatado, sem que isso demande o governo da consciência ou de qualquer outro poder reflexivo, inclusive daquele que, na opinião de Merleau-Ponty, opera no interior da ideia freudiana de defesa contra a castração simbólica.

\section{Expressividade como figurabilidade: do sonho sonhado ao sonho relatado}

Em ao menos dois trabalhos publicados no Brasil, Tamy Ayouch (2012a e 2012b) emprega o significante "figurabilidade" para designar a maneira como, nos termos de uma fenomenologia do afeto, Merleau-Ponty busca descrever 
o vínculo expressivo que comunica o inconsciente simbólico - tal como descrito na esteira de Freud - e a copresença de um horizonte afetivo, como se entre ambos operasse uma unidade ambígua e inacabada que o próprio Merleau-Ponty chamaria de indivisão entre o inconsciente (simbólico) e o consciente (imaginário). Se o sonho sonhado e o sonho relatado comunicamse não é porque sejam habitados por uma mesma consciência, por um mesmo sujeito ou cogito unificador. Antes por que - qual efeito de quiasma - os restos diurnos asseguram entre ambos uma sorte de expressividade, remissão por diferenciação, passagem que os faz parecer investidos de um mesmo tecido.

De fato, para Merleau-Ponty, no caso específico do sonho, tudo se passa como se a copresença dos restos diurnos emprestasse aos significantes recalcados uma fisionomia afetiva, ao mesmo tempo que um estilo narrativo. O que viabiliza que o desejo onírico articulado por aqueles significantes se faça "sentir" e "compreender" no mundo da vigília - mesmo sem precisar ser explicitamente representado como conteúdo manifesto na narrativa que o sonhador elabora logo a seguir, depois do despertar. De onde se segue que, no sonho relatado, a expressão dos significantes recalcados - junto à fisionomia afetiva e ao estilo narrativo emprestados pelos restos diurnos - não tem que ver com uma apropriação mental, não diz respeito à representação cognitiva do conteúdo sonhado. Junto ao conteúdo manifesto, incorporados ao sonho relatado, os significantes recalcados não coincidem com as representações mentais empregadas. Eles estão - antes - expressos junto às imagens afetivas e narrativas, nas quais se apoiam, ainda que a racionalização da vigília outra vez impusesse àqueles significantes o regime do recalcamento, do esquecimento. Conforme Merleau-Ponty (2000, p. 206-207),

O sonhador não começa por representar-se o conteúdo latente de seu sonho, aquele que será revelado pela 'segunda narrativa', com o auxílio de imagens adequadas; ele não começa por perceber claramente as excitações de origem genital como genitais, para em seguida traduzir esse texto em linguagem figurada. Mas para o sonhador, que se desprendeu da linguagem da vigília, tal excitação genital ou tal pulsão sexual é imediatamente esta imagem de um muro que se escala ou de uma fachada na qual se sobe, que se encontra no conteúdo manifesto. A sexualidade se difunde em imagens que só retém dela certas relações típicas, uma certa fisionomia afetiva. $\mathrm{O}$ pênis do sonhador torna-se essa serpente que figura no conteúdo manifesto.

E alcanço outra vez aqui a chave de leitura antes mencionada e por cujo meio tentei mostrar de que modo Merleau-Ponty apropria-se da teoria freudiana do sonho. Ao refletir sobre o papel dos restos diurnos na descarga da libido, ou, o que é a mesma coisa, na realização do simbolismo ao refletir sobre o papel dos restos de memória e dos afetos na conversão do simbolismo em algo 
narrativo e sensível, especificamente afetivo, Merleau-Ponty não simplesmente esclarece de que modo é possível aos significantes recalcados - e articulados de modo inconsciente - encontrarem um objeto para a libido, para a falta que os caracteriza. Merleau-Ponty também esclarece em que sentido, no relato do sonho em estado de vigília, não obstante estarem outra vez recalcados (o que nesta configuração significa dizer: sobredeterminados pelas racionalizações conscientes), os significantes continuam copresentes, ou, ainda, eles continuam expressos junto à fisionomia afetiva e ao estilo narrativo do relato. Seja no sonho sonhado seja no sonho relatado, na medida em que se apoiam nos restos diurnos, os significantes recalcados - ou, o que é a mesma coisa, os significantes sobredeterminados ou esquecidos, porquanto separados de seus valores semânticos - são expressos enquanto polaridade simbólica do sonho. De sorte a se poder admitir, entre a dimensão imaginária (afetiva e narrativa) introduzida pelos restos diurnos, por um lado, e a dimensão simbólica (ou inconsciente) expressa como significante esquecido, por outro, um tipo de unidade sem coincidência, uma indivisão meramente expressiva, que não reedita de forma alguma a ideia de interioridade transparente.

E é por essa indivisão expressiva e não transparente viabilizada pelos restos diurnos que Merleau-Ponty pode asseverar a indivisão - tampouco transparente - entre o sonho sonhado e o sonho relatado. Ou seja, no sonho sonhado, a fisiologia primária residual e a atividade mental remanescente, na qualidade de restos diurnos - e não como produtos ordenados pela lógica específica de cada um desses sistemas - oferecem o lastro sensível e narrativo para a realização dos objetos oníricos. Por outras palavras, no sonho sonhado, os restos diurnos oferecem a base para a catexia entre os representantes ideativos recalcados, o suporte para o encadeamento dos significantes recalcados uns nos outros, de modo a promover a descarga fantasmática da libido, a realização meramente simbólica do desejo. Ou, junto aos afetos e às imagens semânticas retidas como memória evanescente, os significantes recalcados encontram o lastro material e semântico junto ao qual podem se realizar como "objeto fantasmático", de sorte a preencherem e, nesse sentido, aniquilarem a negatividade (própria da libido) que os acompanha e que os faz conectarem-se.

Já no sonho relatado, o panorama narrativo e afetivo assegurado pelos restos diurnos exprime - mais além do recalque imposto pela racionalização consciente - os significantes recalcados que, naqueles, estão apoiados como atividade inconsciente. Mesmo que sobredeterminados pelas significações verbais produzidos na vigília e que constituem o fluxo narrativo do sonho relatado, os significantes recalcados não deixam de se "mostrar", apenas que baralhados, diluídos, misturados ou, simplesmente, expressos junto aos afetos 
e traços de memória degenerada advindos do sonho e que as significações de vigília não conseguem sobredeterminar. Por essa razão, afirma Merleau-Ponty (2000, p. 244),

Não há necessidade de evocação inconsciente de imagens (visuais), porque todo o campo perceptivo interpessoal é tecido de relações de intercorporeidade, porque toda a espacialidade exterior supõe a relação meu corpo-mundo, e então, que o espaço é projeção do eu posso corporal.

Do ponto de vista do sonho relatado, não há necessidade de evocação porque, nos termos de uma indivisão expressiva, o desejo onírico está junto aos restos diurnos e vice-versa, como se pudessem estar um no outro (Ineinender), o que, todavia, não implica que sejam um, mas o vestígio de um no outro, a contaminação de cada qual pela presença do outro. Ou seja, no sonho relatado, junto aos afetos e traços de memória degenerada, o desejo onírico - a conexão inconsciente de significantes recalcados - anuncia-se como horizonte semântico vindouro, mistério a ser desvendado, quase-sentido a ser interpretado, o que nunca corresponde a uma mensagem ou conteúdo determinado, pois se trata de uma conexão inconsciente, de um simbolismo desprovido de amarrações conceituais operadas na vigília. O que impõe ao analista do sonho o desafio de ouvir sem esperar pela compreensão, apenas pela presença afetiva dos significantes brutos.

Aliás, quando me deparo com a posição do analista, preciso me perguntar: quais consequências poderiam se depreender do reconhecimento da conexão expressiva entre o sonho sonhado e o sonho relatado? O que tal reconhecimento poderia representar, por exemplo, para o ofício da interpretação? Afinal, o "sentido" do sonho - conforme a leitura estabelecida por Merleau-Ponty a partir do operador expressivo - já não é mais tão somente uma prerrogativa dos elementos simbólicos que pudessem ser ouvidos como "defesa" contra a repetição da castração simbólica. Conforme aquela leitura, o "sentido" também envolve uma configuração performática, simultaneamente afetiva e narrativa, junto à qual o simbolismo inconsciente adquire ares de existência. Por consequência, o simbolismo inconsciente não pode ser interpretado exclusivamente sob o ponto de vista da "defesa" sistêmica contra a ameaça de sua suposta unidade psíquica. Mesmo porque as narrativas e os afetos conduzem o simbolismo inconsciente a outras "figuras de linguagem", a diferentes figurabilidades, segundo a expressão de Tamy Ayouch. Se é verdade que as narrativas e os afetos tomam do simbolismo inconsciente o ineditismo linguageiro que o define; se é verdade que é tal ineditismo o que eleva a figurabilidade do sonho sonhado à condição de fala falante, inventiva, 
criadora; se é também verdade que somente quando dita de modo falante é que a figurabilidade alcança a condição da singularidade, por outro lado, não haveria como a escuta ao sonho sonhado alcançar o ineditismo simbólico do inconsciente se ele não estivesse expresso junto às narrativas e afetos, seja como tropeço, estranhamento, equívoco ou qualquer outro fenômeno linguageiro. É no panorama amplo da existência formulado como configuração narrativa e afetiva que o simbolismo inconsciente se exprime como diferença. De onde se segue a questão: como interpretar o que se exprime? Como fazê-lo sem reeditar-se os operadores clássicos que justamente a teoria da expressão tentou superar, como aquele que associa a singularidade à identidade ou ao cogito? Mas essa já não é mais uma questão que se possa responder por meio de uma especulação ontológica. Ela exige uma discussão clínica, a qual está mais além do que proponho neste artigo.

\section{Referências}

ABRHAHAM, K. (1924). “Teoria Psicanalítica da libido”. Rio de Janeiro: Imago, 1970. ASSOUN, P.-L. "Freud, la philosophie et les philosophes". Paris: P.U.F., 1976.

"Introduction à la métapsychologie freudienne". Paris: P.U.F., 1993.

AYOUCH, T. "Genealogia da intersubjetividade e figurabilidade do afeto: Winnicott e Merleau-Ponty”. Psicologia USP, Vol. 13, Nr. 2, pp. 253-274, $2012 \mathrm{a}$.

. "Merleau-Ponty e a psicanálise: da fenomenologia da afetividade à figurabilidade do afeto". Jornal de Psicanálise, Vol. 45, Nr. 83, São Paulo, dez. 2012 b.

BRENTANO, F. (1874). «Psychologie du point de vue empirique». Trad. M. Gandillac. Revision par J.-F. Courtine. Paris: Vrin, 1874 (edição de 2008).

DESCARTES, René. (1641). "Meditações". Prefácio e notas de Gérard Lebrun, Trad. J. Guinsburg e B. Prado Júnior. 2. ed. São Paulo: Abril Cultural, 1979 (Os pensadores). FREUD, S. "Edição Standard Brasileira das Obras Psicológicas Completas de Sigmund Freud" [ESB]. Rio de Janeiro: Imago, 1970-1977.

. v. I (1895-1950), "Projeto para uma psicologia científica".

. v. II (1893-1895), "Estudos sobre a hysteria”, 1974.

. v. III (1898), "O mecanismo psíquico do esquecimento", 1976.

. vs. IV e V (1900), "A interpretação de sonhos", 1972.

. v. VII (1905), "Três ensaios sobre a sexualidade", 1972.

. v. XI (1910), "Cinco lições de psicanálise", 1970.

. v. XIV (1915), "Repressão", 1974.

. v. XIV (1917), "Suplemento metapsicológico à teoria dos sonhos", 1974.

. vs. XV e XVI (1916- 1917), "Conferências introdutórias sobre psicanálise”, 1976.

. v. XVII (1918), "História de uma neurose infantile", 1976.

. v. XVIII (1920), “Além do princípio de prazer", 1976.

. v. XVIII (1923), “A psicanálise” (1923), “A teoria da libido”, 1976. 
. v. XXII (1933), “Novas conferências introdutórias sobre psicanálise”, 1976.

HUSSERL, E. (1917). "Lições para uma fenomenologia da consciência interna do tempo". (P. M. S. Alves, Trad.). Lisboa: Imprensa Nacional - Casa da Moeda. 1994 (Trabalho original publicado em 1917).

HUSSERL, E. Meditações cartesianas. Rés Editora, 1931.

LEFORT, C. 'L'idée de l'ètrê brut et d'esprit sauvage". Les Temps Modernes, Vol. 17, Nr. 184-185, pp. 273-292, 1961.

LEIBNIZ, G. W. (1714). "Princípios de Filosofia ou Monadologia”. Trad. L. Martins. Lisboa, Imprensa Nacional/Casa da Moeda, s.d.

LOCKE, J. "Ensaio acerca do entendimento humano". Livro II, Cap. XXIII. Trad. A. Aiex e E. J. Monteiro. 2. ed. São Paulo: Abril Cultural, 1978.

MERLEAU-PONTY, M. "La Structure du comportement”. Paris: PUF, 1942.

. "Phénoménologie de la perception". Paris: Gallimard, 1945.

. "Éloge de la philosophie et autres essais". Paris: Gallimard, 1953.

. "Signes". Paris: Gallimard, 1960a.

. (1960b). "Préface à L'œuvre et l'Esprit de Freud”. In: Parcours deux. 1951-

1961. Paris: Verdier, 2000.

. "Candidature au Collège de France - Un inédit de Merleau-Ponty". Revue de métaphysique et de morale, Vol. 67, pp. 401-409, 1962.

. "Le visible et l'invisible". Paris: Gallimard, 1964a.

. "L'oeil et l'esprit". Paris: Gallimard, 1964b.

. "Sens et non-sens". Paris: Nagel, 1966.

. "Résumés de cours. Collège de France 1952-1960”. Paris: Gallimard, 1968.

. "La Prose du monde". Paris: Gallimard, 1969.

. "Merleau-Ponty à la Sorbonne: résumé de cours - 1949-52”. Grenoble: Cynara, 1989.

. "La Nature - Notes de cours du Collège de France. Établi et annoté par Dominique Séglard”. Paris: Seuil, 1995.

. "Notes de cours: Collège de France - 1959-1961". Paris: Gallimard, 1996.

. "Notes de cours sur l'origine de la géométrie de Husserl". Paris: PUF, 1998.

. "L'Institution. La passivité. Notes de cours au Collège de France. 1954-1955".

Tours: Belin, 2000.

SARTRE, J. P. (1940). “O imaginário: psicologia fenomenológica da imaginação”. São Paulo: Ática, 1996.

. (1942). “O Ser e o Nada”. Trad. P. Perdigão. Petrópolis, Vozes, 2000. 